\title{
Caracterização bromatológica e agronômica de genótipos de milho para produção de silagem
}

\author{
[Chemical characterization and agronomic genotypes of maize for silage] \\ V.C. Vieira, T.N. Martin*, L.F.G. Menezes, T. Assmann, S. Ortiz, P. Bertoncelli, \\ F.A. Piran Filho, T.H. Schimitz
}

Universidade Federal de Santa Maria - Centro de Ciências Rurais - Santa Maria, RS

\begin{abstract}
RESUMO
O objetivo deste trabalho foi avaliar as características bromatológicas e agronômicas dos genótipos de milho para a produção de silagem dos cultivares do Ensaio Centro Superprecoce da Rede Nacional de Genótipos de Milho, bem como avaliar se a base genética (híbridos simples, duplos, tripos, intervarietais e variedades cultivadas) ou a dureza dos grãos (duro, semiduro e dentado mole) alteram a indicação de cultivares de milho para silagem. $\mathrm{O}$ experimento foi realizado na área experimental da Universidade Tecnológica Federal do Paraná (campus Dois Vizinhos). Os trinta e dois genótipos avaliados foram colhidos quando os grãos encontravam-se no estádio pastoso a farináceo, ensilados em microssilos de PVC e desensilados após 53 dias. Avaliou-se a relação entre as bases genéticas, a dureza do grão e as características individuais dos genótipos quanto à aptidão para a produção de silagem. Não se verificaram diferenças significativas entre os contrastes formados entre as bases genéticas, bem como a dureza dos grãos, para os caracteres estudados. Porém, foi possível identificar genótipos superiores para a produção de silagem pela produção de matéria seca pelos genótipos AS 1555 YG, AS 1572 YG, 30A37, 30A77, 20A78, Dx 908, Dx 603, 2A550, 2B433, AL2007A, Embrapa 1F640, PRE 22T10, PREXT0109, PRE 22D11, DKB330 YG (Test).
\end{abstract}

Palavras-chave: base genética, dureza do grão, indicação de cultivares

\begin{abstract}
The aim of this study was to evaluate the nutritive value and agronomic characteristics of maize genotypes for the silage production cultivars test center network of Super Early National Corn Genotypes; and to assess whether the genetic background (hybrids simple, doubles, triples, intervarieties and cultivated varieties) or the hardness of the grains (hard, soft flint and dent) may change the indication of maize cultivars for silage. The experiment was conducted at the experimental Federal Technological University of Paraná (Campus Dois Vizinhos). Thirty-two genotypes were harvested when the grains were in the dough soft dough stage, micro-ensiled in PVC silos, silage cutters and after 53 days after silage cutters. We evaluated the characteristics and chemical plant parameters of each genotype. We evaluated the relationship between genetic bases, hardness of the grain and individual characteristics of genotypes related to the production of corn silage. There was no significant difference between the contrast formed between the genetic and hardness of the grains for the characteristics studied. However, it was possible to identify superior genotypes for the production of silage whit bases in dry matter production by genotype YG AS 1555, AS 1572 YG, 30A37, 30A77, 20A78, DX 908, DX 603, 2A550, 2B433, AL2007A, EMBRAPA 1F640, PRE 22T10, PREXT0109, PRE 22D11, DKB330 YG (Test).
\end{abstract}

Keyword: genetic basis of grain hardness, indicating cultivars

Recebido em 15 de junho de 2011

Aceito em 5 de julho de 2012

*Autor para correspondência (corresponding author)

E-mail: martin.ufsm@gmail.com 


\section{INTRODUÇÃO}

A produção leiteira no sul do Brasil caracterizase por ser, predominantemente, realizada em pequenas propriedades, onde $92 \%$ delas possuem menos de 50 hectares (Instituto..., 2009). Uma das principais dificuldades para esses produtores é a estacionalidade da produção forrageira, existindo, assim, a necessidade de suplementação alimentar para o rebanho nas épocas de escassez (Mello et al., 2004). Entre as alternativas de suplemento volumoso, a silagem é a mais utilizada.

A produção de massa por unidade de área e a qualidade nutricional para os animais são os critérios utilizados para a escolha da espécie forrageira para a produção de silagem. Por isso, o milho é a forrageira mais utilizada para produzir silagem. Autores como Bal et al. (2000) e Beleze et al. (2003) destacam as características médias e necessárias que fazem com que a planta de milho seja considerada uma excelente forrageira para produção de silagem.

Para a safra 2009/2010 foram disponibilizados no mercado 325 cultivares de milho convencionais e 104 transgênicos, havendo cultivares com recomendação para produção de silagem. Entretanto, tem sido observada a existência de variabilidade tanto para a produtividade de matéria seca, produção de grãos quanto para a qualidade da silagem (Embrapa, 2010). Estas características são afetadas pela interação dos genótipos com o ambiente, sendo necessária a avaliação destes genótipos em diferentes locais, que tenham representatividade para as principais regiões de produção de silagem. A busca de genótipos com melhores características fitomorfológicas de interesse para a produção de silagem tem sido motivo de diversas pesquisas (Flaresso et al., 2000; Souza et al. 2000; Beleze et al., 2003; Jaremtchuk et $a l ., 2005)$, direcionando o sistema produtivo para melhores resultados. Porém, são limitados os estudos que comparam os genótipos quanto à textura dos grãos (diferentes texturas entre si) e à base genética (diferentes bases genéticas entre si), mesmo havendo indícios de que esses podem ser fatores determinantes para a produção da cultura.
Desta forma, objetivou-se com este trabalho avaliar as características bromatológicas e agronômicas dos genótipos de milho para a produção de silagem das cultivares do Ensaio Centro Superprecoce da Rede Nacional de Genótipos de Milho, bem como avaliar se a base genética (híbridos simples, duplos, tripos, intervarietais e variedades cultivadas) ou a dureza dos grãos (duro, semiduro e dentado mole) podem alterar a indicação de cultivares de milho para silagem.

\section{MATERIAL E MÉTODOS}

O experimento foi conduzido na área experimental da Universidade Tecnológica Federal do Paraná (UTFPR), campus Dois Vizinhos. A região compreende o terceiro planalto paranaense, com altitude de $520 \mathrm{~m}$, latitude de $25^{\circ} 44^{\prime \prime}$ sul e longitude de $53^{\circ} 04^{\prime \prime}$ oeste. O clima predominante é do tipo subtropical úmido mesotérmico (Cfa), segundo a classificação de Köppen. $\mathrm{O}$ solo pertence à unidade de mapeamento nitossolo vermelho distroférrico úmbrico, textura argilosa fase floresta subtropical perenifólia, relevo ondulado (Santos et al., 2008). Foram avaliados todos os 32 genótipos do ciclo Superprecoce, Ensaio Centro (Tab. 1), fornecidos pela Embrapa Milho e Sorgo (Sete Lagoas, MG), que constituem os ensaios de competição de cultivares de milho do Brasil.

O experimento foi semeado em 23 de outubro de 2009, colocando-se duas sementes por cova, ajustando-se posteriormente para 58.000 plantas por hectare. As parcelas foram compostas por duas fileiras de $5 \mathrm{~m}$ de comprimento, espaçadas $75 \mathrm{~cm}$ entre fileiras e, aproximadamente, $23 \mathrm{~cm}$ entre plantas. A adubação de base foi realizada 15 dias antes da semeadura e consistiu de $20 \mathrm{~kg} / \mathrm{ha}$ de ureia, $100 \mathrm{~kg} / \mathrm{ha}$ de superfosfato simples e $20 \mathrm{~kg} / \mathrm{ha}$ de cloreto de potássio. A adubação de cobertura foi realizada quando as plantas apresentavam, em média, de cinco a seis folhas utilizando-se $80 \mathrm{~kg} / \mathrm{ha}$ de $\mathrm{N}$ (ureia, $45 \%$ de $\mathrm{N}$ ). $\mathrm{O}$ controle de plantas daninhas foi realizado com aplicação do herbicida atrazina (6chloro-N²-ethyll-N4-isopropyl-1,3,5-triazine-2,4diamine), na dosagem de $5 \mathrm{~L} / \mathrm{ha}$. O inseticida utilizado foi Lanate BR (S-methyl Nmethylcarbamoyloxy) thioacetimidate), na dosagem de $0,3 \mathrm{~L} / \mathrm{ha}$. 
Caracterização bromatológica...

Tabela 1. Genótipos (GEN), nome comercial, base genética (BG), dureza do grão (DG), empresa produtora (EMP) dos genótipos pertencentes ao Ensaio Centro Superprecoce

\begin{tabular}{cccccccccc}
\hline Gen. & Nome comercial & BG* & DG** & EMP*** & Gen. & Nome comercial & BG & DG & EMP \\
\hline 1 & AS 1555 YG & HS & NI & AGR & 17 & BRS Sint. Super & VAR & SD & BRS \\
2 & AS 1572 YG & HS & SD & AGR & 18 & GNZ 2500 & HS & NI & GNZZ \\
3 & AS 1578 YG & HS & SD & AGR & 19 & GNZX 0743 & HS & SD & GNZZ \\
4 & $30 A 37$ & HS & SD & AGN & 20 & PRE 12S12 & HS & SD & PRE \\
5 & $30 A 77$ & HS & NI & AGN & 21 & PRE 22S11 & HS & SD & PRE \\
6 & 20A78 & HT & SD & AGN & 22 & PRE 22T10 & HT & SD & PRE \\
7 & Dx 908 & HS & D & DX & 23 & PRE 22T12 & HT & SD & PRE \\
8 & Dx 603 & HT & SD & DX & 24 & PREXT0109 & HT & DM & PRE \\
9 & 2A550 & HT & SD & DOW & 25 & PRE 22D11 & HD & SD & PRE \\
10 & 2B587 & HS & SD & DOW & 26 & SHS-7090 & HS & SD & SHS \\
11 & 2B433 & HS & NI & DOW & 27 & SHS-7111 & HS & SD & SHS \\
12 & AL2007A & VAR & SD & CATI & 28 & XBX80822 & HS & SD & SEMEALI \\
13 & H2002ALTA & HI & D & CATI & 29 & AG9040 (Test) & HS & SD & BRS \\
14 & H25ALTA & HI & SD & CATI & 30 & Dow 2A106 (Test) & HS & SD & BRS \\
15 & EMBRAPA 1F640 & HS & NI & BRS & 31 & BRS3035 (Test) & HT & SD & BRS \\
16 & BRS Gorutuba & VAR & NI & BRS & 32 & DKB330 YG (Test) & HS & D & BRS \\
\hline
\end{tabular}

*Base genética: HS - híbrido simples, HT - híbrido triplo, Var - variedade, HD - híbrido duplo, HI - híbrido intervarietal; **dureza do grão: NI - não informado, SD - semiduro, D - duro, DM - dentado mole; *** empresas: AGR: Agroeste; DT: Delta; BRS: Embrapa; PRE: Prezzotto; SHS: Santa Helena Sementes; AGN: Agromen Tecnologia; GNZ: Gêneze Sementes; DOW: Dow AgroSciences; DSMM/CATI; AG: Agroceres; DKB: Dekalb e SEMEALI: Semeali.

Os caracteres avaliados foram: número de dias para o florescimento (DF), estatura das plantas $(\mathrm{EP}, \mathrm{m})$, estatura de inserção da primeira espiga (EE, m) e diâmetro de colmo (DC, cm); os genótipos foram medidos um dia antes da colheita e, nesta oportunidade, foram contados o número total de plantas da parcela (NP) e o número de plantas quebradas mais as acamadas (NPQA) que posteriormente foram extrapoladas para hectare. A colheita foi realizada em 20/01/2010 e consistiu no corte das plantas da parcela a $30 \mathrm{~cm}$ da superfície do solo. A colheita foi realizada quando os grãos da espiga apresentavam-se no estádio pastoso a farináceo. As plantas, depois de colhidas, foram pesadas em balança digital, separando-se uma planta para as avaliações fitotécnicas (fracionamento de colmo, folhas e espiga), sendo mensurados os seguintes caracteres: matéria verde ( $\mathrm{MV}, \mathrm{kg} / \mathrm{ha})$, porcentagem de matéria seca do colmo (MSCOL, \%), de lâmina foliar verde (MSFV, $\%$ ), de espiga (MSESP, \%), das plantas trituradas para silagem (MSST, \%), matéria seca do material ensilado (MSSENS, \%), liberação de efluentes (EF, gramas), matéria seca de planta total (MSPL, \%) e matéria seca por hectare (MSH, t/ha). O restante do material foi triturado utilizando-se ensiladeira JF 90 acoplada a um trator, com regulagem para o tamanho de partícula de $1,5 \mathrm{~cm}$. Após trituração do material, retirou-se uma amostra para determinação de matéria seca; esta foi colocada em estufa de circulação forçada a $55^{\circ} \mathrm{C}$ até massa constante. Os caracteres bromatológicos foram avaliados por meio da espectrometria de reflectância no infravermelho proximal (NIRS) (Berzaghi et al., 1997), sendo eles: umidade (UM, \%), matéria seca original (MSO, \%), proteína bruta (PB, \%), fibra em detergente ácido (FDA, \%), fibra em detergente neutro (FDN, \%), nutrientes digestíveis totais (NDT, \%), energia líquida de lactação (ELL, Mcal/kg MS).

Os dados foram submetidos à análise dos pressupostos do modelo matemático (aditividade, normalidade, homogeneidade de variância e independência dos erros), segundo aplicações de Martin e Storck (2008), e, posteriormente, à análise de variância, de acordo com o delineamento láttice, com duas repetições e conforme as recomendações da Embrapa (Milho e Sorgo), organizadora dos ensaios de competição de cultivares. As médias das bases genéticas [híbrido simples (HS), híbrido trilho (HT), híbrido duplo (HD), híbrido intervarietal (HI) e variedade cultivada (VAR)] foram comparadas, entre si, por meio de contrastes (Scheffée). Os contrastes formados entre as 
médias das distintas bases genéticas foram: HSHT; HS-HD; HS-VAR; HS-HI; HT-HD; HTVAR; HT-HI; HD-VAR; HD-HI e VAR-HI. Posteriormente foi feita a comparação entre as médias dos grupos de milho [duro (D), semiduro (SD), dentado (DM)], pelo mesmo teste, formando os seguintes grupos de contrastes: SDD; SD-DM e D-DM. Os genótipos foram comparados entre si, por meio do teste de ScottKnott, a 5\% de probabilidade de erro, utilizandose o software Genes (Cruz, 2006).

\section{RESULTADOS E DISCUSSÕES}

O experimento foi conduzido de modo que não tenha sido influenciado por pragas, doenças e plantas daninhas, resultados do controle químico aplicado. No que diz respeito às pressuposições do modelo matemático (aditividade, homogeneidade de variância, normalidade e aleatoriedade), verificou-se que nenhuma das pressuposições foi violada em nenhum dos caracteres avaliados, conferindo, assim, qualidade aos resultados experimentais (Martin e Storck, 2008).

Os genótipos avaliados neste trabalho, quando submetidos ao teste de contraste de Scheffeé (médias dos diferentes grupos formados pelas bases genéticas), não apresentaram diferenças significativas para os caracteres agronômicos e bromatológicos (Tab. 2 e Tab. 3), exceto para a variável massa seca de espiga, na comparação do grupo de genótipos do híbrido simples e de variedade cultivada. Os ensaios de competição de cultivares são organizados pela Embrapa (Milho e Sorgo) e avaliaram os genótipos disponíveis no mercado que foram submetidos para o ensaio de competição de cultivares referentes ao Ensaio Centro de Ciclo Superprecoce. Segundo Nussio et al. (2001), a análise histórica sugere que os programas de melhoramento devem se preocupar com o valor nutritivo proveniente das porções vegetativa e espiga. Esses mesmos autores ponderam que a qualidade da espiga faz parte dos objetivos de programa de pesquisa com milho para silagem em instituições internacionais.

Freitas et al. (2008), ao compararem cinco genótipos em elevado nível tecnológico, verificaram que o híbrido simples foi superior a um híbrido duplo (25A23) e a uma variedade, porém teve o mesmo desempenho que um híbrido simples modificado e outro híbrido duplo (RG2A). Essa condição de resposta não é unanimidade na literatura, pois nem sempre os híbridos simples são superiores às outras bases genéticas. Provavelmente existe variabilidade dentro de cada base genética, o que pode alterar os resultados obtidos a campo. Além disso, essa variabilidade é alterada em razão do ambiente. No presente caso, as condições ambientais podem ter sido satisfatórias para algumas bases genéticas ao requerimento de outras, fazendo com que, em média, não exista diferença entre as bases genéticas testadas.

No que diz respeito aos contrastes entre os tipos de grãos (semiduro, duro e dentado mole), verificou-se que não houve efeito significativo para nenhum dos contrastes observados (Tab. 3).

O mesmo resultado foi observado por Rossi Júnior et al. (2006), em trabalho avaliando dois híbridos de diferentes grupos de grãos (dentado e semidentado), em que não obtiveram diferença significativa nas variáveis bromatológicas (matéria seca, proteína bruta, fibra em detergente neutro e fibra em detergente ácido), apenas na digestibilidade.

Infere-se que, nesse sentido, também haja uma variabilidade dentro de cada grupo. Nesse aspecto, também não se verifica um consenso entre resultados de pesquisa, havendo divergências na literatura. Contudo, autores como Moraes et al. (2008) verificaram que o híbrido de textura dentada possui maior produção de massa seca que os híbridos de textura dura (18.829 a $20.400 \mathrm{~kg} \mathrm{ha}^{-1}$, respectivamente), semelhantes aos resultados obtidos por Flaresso et al. (2000), que obtiveram produções entre 18.092 e $23.869 \mathrm{~kg} \mathrm{ha}^{-1}$. Porém, os estudos apresentados na literatura utilizam poucos genótipos, que são selecionados pelo pesquisador, contrapondo-se à presente pesquisa, a qual utilizou todos os genótipos referentes ao Ciclo Superprecoce e Ensaio Centro. Dessa forma, ao se selecionarem genótipos, pode haver uma facilidade de detecção de diferenças significativas, pois os experimentos comparam genótipos e não grupos como os comparados neste estudo. 
Tabela 2. Diferença entre as médias das bases genéticas do Ensaio Centro Superprecoce

\begin{tabular}{|c|c|c|c|c|c|c|}
\hline Caracteres & HS-HT $^{\text {ns }}$ & $\mathrm{HS}-\mathrm{HD}^{\mathrm{ns}}$ & HS-VAR $^{\mathrm{ns}}$ & HS-HI $^{\mathrm{ns}}$ & HT-HD ${ }^{\mathrm{ns}}$ & $\mathrm{HT}^{-V A R^{\mathrm{ns}}}$ \\
\hline $\mathrm{DF}^{*}$ & 0,301 & $-0,509$ & $-0,143$ & 0,158 & 0,158 & $-0,810$ \\
\hline $\mathrm{EP}$ & $-0,004$ & 0,125 & $-0,018$ & $-0,022$ & $-0,085$ & 0,129 \\
\hline $\mathrm{EE}$ & 0,029 & 0,099 & $-0,035$ & $-0,006$ & $-0,064$ & 0,070 \\
\hline DC & 0,018 & 0,194 & $-0,047$ & $-0,029$ & $-0,094$ & 0,176 \\
\hline NP & -2331 & 526 & 12857 & 10526 & -1259 & 2857 \\
\hline NPQA & -1584 & -4850 & -6837 & -8421 & 151 & -3266 \\
\hline MV & -4548 & 9492 & 14830 & 10282 & -9979 & 14040 \\
\hline MSCOL & 0,009 & $-0,019$ & $-0,009$ & 0,000 & 0,034 & $-0,028$ \\
\hline MSFV & $-0,010$ & $-0,024$ & $-0,024$ & $-0,034$ & $-0,006$ & $-0,014$ \\
\hline MSESP & $-0,026$ & $-0,033$ & $-0,196 * *$ & $-0,222$ & 0,011 & $-0,007$ \\
\hline MSST & $-0,002$ & $-0,015$ & $-0,022$ & $-0,024$ & 0,012 & $-0,013$ \\
\hline MSSENS & 0,004 & $-0,013$ & $-0,009$ & $-0,005$ & 0,018 & $-0,017$ \\
\hline $\mathrm{EF}$ & 27 & 7 & -150 & -123 & -7 & -20 \\
\hline MSPL & $-0,007$ & $-0,024$ & $-0,066$ & $-0,073$ & 0,027 & $-0,017$ \\
\hline MSH & $-1,840$ & 2,231 & 1,478 & $-0,362$ & $-1,382$ & 4,071 \\
\hline UM & $-0,200$ & 0,456 & 0,089 & $-0,111$ & $-1,321$ & 0,656 \\
\hline MSO & 0,200 & $-0,456$ & $-0,089$ & 0,111 & 1,321 & $-0,656$ \\
\hline PB & $-0,034$ & $-0,268$ & 0,311 & 0,277 & 0,254 & $-0,234$ \\
\hline FDA & 0,226 & $-0,549$ & $-3,310$ & $-3,084$ & $-5,017$ & $-0,775$ \\
\hline FDN & 0,387 & $-0,678$ & $-4,200$ & $-3,813$ & $-6,261$ & $-1,065$ \\
\hline NDT & $-0,200$ & 0,357 & 2,205 & 2,005 & 3,335 & 0,557 \\
\hline ELL & $-0,007$ & 0,016 & 0,091 & 0,084 & 0,139 & 0,023 \\
\hline
\end{tabular}

*HS: híbrido simples; HT: híbrido triplo; HD: híbrido duplo; HI: Híbrido intervarietal; VAR: variedade cultivada, para os caracteres número de dias para o florescimento (DF), estatura de planta (EP, m) e de espiga (EE, m), diâmetro de colmo (DC, cm), número de plantas por hectare (NP), número de plantas/ha, quebradas mais acamadas (NPQA) e matéria verde (MV, $\mathrm{kg} / \mathrm{ha}$ ), matéria seca do colmo (MSCOL, \%), matéria seca de folha verde (MSFV, \%), matéria seca de espiga (MSESP, \%), matéria seca das plantas trituradas para silagem (MSST, \%), matéria seca do material ensilado (MSSENS, \%), liberação de efluentes (EF, gramas) e matéria seca de planta total (MSPL, \%), matéria seca por hectare (MSH, \%), umidade (UM, \%), matéria seca original (MSO, \%), proteína bruta (PB, \%), fibra em detergente ácido (FDA, \%), fibra em detergente neutro (FDN, \%), nutrientes digestíveis totais (NDT, \%), energia líquida de lactação (ELL, Mcal/kg MS).

** ns: significativo e não significativo pelo teste de Scheffe $(\mathrm{P}<0,05)$, respectivamente.

O número de genótipos avaliados representa a totalidade dos genótipos submetidos para a avaliação pela Embrapa (Milho e Sorgo) no referido ano, fazendo com que os resultados sejam representativos para os genótipos do grupo Centro, Ciclo Superprecoce.

Pelo fato de não se verificarem diferenças entre os grupos (exceto para um caractere), tanto no que se refere às bases genéticas quanto à dureza do pericarpo dos grãos, compararam-se os genótipos pelo teste de Scott-Knott (Tab. 4 e Tab. 5). Os caracteres que apresentaram diferença significativa foram: número de plantas quebradas e acamadas, produção de matéria verde, teor de matéria seca da espiga, teor de matéria seca da planta inteira e produção de matéria seca. Entre essas variáveis, a produção de matéria seca se destaca. Uma vez que a composição bromatológica foi semelhante para todos os genótipos, a escolha dos híbridos mais produtivos deve ser realizada com base na produção de matéria seca. Conforme Bruno et al. (1989), a produção de silagem de alta qualidade depende, entre outros fatores, do rendimento de matéria seca associado às qualidades nutricionais da massa ensilada. 
Tabela 3. Diferença entre as médias das bases genéticas e textura dos grãos

\begin{tabular}{|c|c|c|c|c|c|c|c|}
\hline Caracteres & $\mathrm{HT} \mathrm{HI}^{\mathrm{ns}}$ & HD-VAR $^{\mathrm{ns}}$ & $\mathrm{HD} \mathrm{HI}^{\mathrm{ns}}$ & VAR-HI $^{\mathrm{ns}}$ & SD-D ${ }^{\mathrm{ns}}$ & $\mathrm{SD} \mathrm{DM}{ }^{\mathrm{ns}}$ & $\mathrm{D}^{-D M^{n s}}$ \\
\hline DF & $-0,15$ & $-0,66$ & 0 & 0,66 & $-0,076$ & 0,591 & 0,667 \\
\hline EP & $-0,08$ & 0,15 & $-0,06$ & $-0,21$ & $-1,087$ & 0,01 & $-0,005$ \\
\hline EE & $-0,092$ & 0,105 & $-0,06$ & $-0,16$ & 1,097 & $-0,017$ & $-0,012$ \\
\hline DC & $-0,11$ & 0,23 & $-0,06$ & $-0,29$ & $-0,149$ & $-0,112$ & 0,037 \\
\hline NP & 1071 & -10000 & -11786 & -1786 & -3204 & -3442 & -238 \\
\hline NPQA & 1735 & 3572 & 8572 & 5000 & 2414 & 5747 & 3333 \\
\hline MV & -5431 & -790 & -20261 & -19471 & -6284 & -16016 & -9732 \\
\hline MSCOL & 0,025 & $-0,019$ & 0,034 & 0,053 & 0,026 & 0,02 & $-0,006$ \\
\hline MSFV & 0,003 & 0,01 & 0,027 & 0,017 & 0,006 & $-0,004$ & $-0,01$ \\
\hline MSESP & 0,036 & 0,189 & 0,232 & 0,043 & 0,024 & 0,008 & $-0,016$ \\
\hline MSST & 0,014 & 0,009 & 0,036 & 0,027 & $-0,014$ & $-0,024$ & $-72,622$ \\
\hline MSSENS & 0,014 & $-0,009$ & 0,022 & 0,031 & 0,009 & $-0,003$ & $-0,012$ \\
\hline $\mathrm{EF}$ & -34 & 130 & 116 & -14 & 22 & -62 & -84 \\
\hline MSPL & 0,033 & 0,049 & 0,099 & 0,051 & 0,019 & 0,009 & $-0,01$ \\
\hline MSH & 0,458 & 2,593 & $-1,019$ & $-3,612$ & $-0,831$ & $-4,387$ & $-3,556$ \\
\hline UM & $-1,12$ & 0,575 & $-1,21$ & $-1,78$ & 0,034 & 2,912 & 2,878 \\
\hline MSO & 1,12 & $-0,565$ & 1,21 & 1,78 & $-0,034$ & $-2,912$ & $-2,878$ \\
\hline PB & 0,29 & $-0,545$ & $-0,02$ & 0,53 & $-0,142$ & $-0,947$ & $-0,805$ \\
\hline FDA & $-5,24$ & 2,535 & $-1,93$ & $-4,46$ & 1,234 & 6,199 & 4,965 \\
\hline FDN & $-6,64$ & 3,14 & $-2,44$ & $-5,58$ & 2,538 & 7,181 & 4,643 \\
\hline NDT & 3,54 & $-1,645$ & 1,33 & 2,98 & $-0,809$ & $-4,109$ & $-3,3$ \\
\hline ELL & 0,15 & $-0,06$ & 0,06 & 0,12 & $-0,04$ & $-0,17$ & $-0,13$ \\
\hline
\end{tabular}

HT: híbrido triplo; HI: híbrido intervarietal; HD: híbrido duplo; VAR: variedade cultivada; D: duro; SD: semiduro; DM: dentado, para os caracteres número de dias para o florescimento (DF), estatura de planta (EP, m) e de espiga (EE, m), diâmetro de colmo (DC, $\mathrm{cm}$ ), número de plantas por hectare (NP), número de plantas quebradas mais acamadas (NPQA) e matéria verde (MV, $\mathrm{kg} / \mathrm{ha})$, matéria seca do colmo (MSCOL, \%), matéria seca de folha verde (MSFV, \%), matéria seca de espiga (MSESP, \%), matéria seca das plantas trituradas para silagem (MSST, \%), matéria seca do material ensilado (MSSENS, \%), liberação de efluentes (EF, gramas) e matéria seca de planta total (MSPL, \%), matéria seca por hectare (MSH, t/ha), umidade (UM), matéria seca original (MSO, \%), proteína bruta ( $\mathrm{PB}, \%)$, fibra em detergente ácido (FDA, \%), fibra em detergente neutro (FDN, \%), nutrientes digestíveis totais (NDT, \%), energia líquida de lactação (ELL).

ns: não significativo pelo teste de Scheffe $(\mathrm{P}<0,05)$.

A diferenciação quanto ao teor de matéria seca se deve, principalmente, ao fato de a determinação do ponto de colheita ter se baseado apenas no estádio do grão, sem levar em consideração as variações quanto aos demais componentes da planta, como a maturidade das folhas e o conteúdo de água no colmo. Segundo Van Soest (1994), o teor de matéria seca influencia a intensidade do processo fermentativo da silagem, em que o menor teor de umidade, associado à maior tensão osmótica, decorrente da concentração de nutrientes, inibe o surgimento de fermentações indesejáveis, causadas por bactérias clostrídicas, sem prejudicar a fermentação lática (Mülbach, 1999). O teor de matéria seca ideal para ensilagem varia entre 30 e $35 \%$ de matéria seca (Van Soest, 1994), evitando perdas pela formação de efluentes e produção de gases, água e calor, objetivando, assim, adequada fermentação lática para manutenção do valor nutritivo da silagem (Rosa et al., 2004). No presente estudo, observaram-se alguns híbridos com teores de matéria seca abaixo dos $30 \%$, porém sem diferenças para produção de efluentes. Senger et al. (2005) concluíram que silagens de milho muito úmidas, além de produzirem efluentes, podem transformar uma grande parte do nitrogênio em nitrogênio insolúvel. Isso ocorre pela perda de nutrientes solúveis nos efluentes. Teores de matéria seca acima de $35 \%$ também podem atrapalhar o processo de compactação, fazendo com que camadas de oxigênio fiquem dentro do silo e ocorra fermentação anaeróbica, indesejável na produção de silagens de qualidade. Os resultados experimentais concordam parcialmente com os apresentados por Mello et al. (1999), os quais, ao avaliarem 30 cultivares de milho de base genética híbrido de diversas bases genéticas, encontraram diferenças estatísticas apenas na produção de MS (12,49 a 20,59t ha-1) e na porcentagem de espigas na matéria verde $(44,29$ a $34,33 \%)$, não havendo diferenças estatísticas nas variáveis altura de plantas, altura de inserção de espigas, FDN e FDA. 
Caracterização bromatológica...

Tabela 4. Média dos caracteres avaliados dos genótipos do Ensaio Centro Superprecoce

\begin{tabular}{|c|c|c|c|c|c|c|c|c|c|c|c|c|c|}
\hline Gen & DF & EP & $\mathrm{EE}$ & DC & NP & \multicolumn{2}{|c|}{ NPQA } & \multicolumn{2}{|c|}{ MV } & MSCOL & MSFV & \multicolumn{2}{|c|}{ MSESP } \\
\hline 1 & 68,00 & 2,66 & 1,39 & 2,31 & 61429 & 715 & $\mathrm{c}^{*}$ & 77837 & $\mathrm{a}$ & 22,0 & 23,0 & 48,1 & $\mathrm{~b}$ \\
\hline 2 & 69,00 & 2,56 & 1,27 & 1,94 & 60000 & 715 & $\mathrm{c}$ & 61398 & $\mathrm{~b}$ & 27,2 & 26,3 & 47,8 & b \\
\hline 3 & 67,50 & 2,50 & 1,20 & 2,04 & 61429 & 5000 & $\mathrm{c}$ & 55820 & $\mathrm{c}$ & 22,5 & 23,3 & 44,0 & b \\
\hline 4 & 67,00 & 2,37 & 1,30 & 2,29 & 62143 & 0 & $\mathrm{c}$ & 75641 & $\mathrm{a}$ & 21,5 & 25,0 & 48,9 & b \\
\hline 5 & 66,00 & 2,47 & 1,40 & 2,19 & 61429 & 1429 & $\mathrm{c}$ & 63739 & $\mathrm{~b}$ & 26,5 & 24,8 & 48,2 & b \\
\hline 6 & 67,50 & 2,44 & 1,37 & 2,11 & 64286 & 3572 & $\mathrm{c}$ & 71590 & $\mathrm{a}$ & 19,3 & 23,4 & 51,0 & b \\
\hline 7 & 68,00 & 2,53 & 1,46 & 2,27 & 56429 & 715 & $\mathrm{c}$ & 61255 & b & 33,1 & 25,2 & 46,5 & b \\
\hline 8 & 68,00 & 2,33 & 1,16 & 2,19 & 63572 & 2143 & $\mathrm{c}$ & 68061 & $\mathrm{~b}$ & 26,8 & 22,0 & 53,2 & b \\
\hline 9 & 67,50 & 2,36 & 1,37 & 2,25 & 58572 & 1429 & $\mathrm{c}$ & 62882 & $\mathrm{~b}$ & 23,3 & 25,6 & 52,6 & b \\
\hline 10 & 67,00 & 2,25 & 1,23 & 2,35 & 56429 & 5715 & $\mathrm{c}$ & 52411 & $\mathrm{c}$ & 28,2 & 25,3 & 47,2 & b \\
\hline 11 & 67,00 & 2,34 & 1,23 & 2,04 & 62857 & 5000 & $\mathrm{c}$ & 66093 & $\mathrm{~b}$ & 21,7 & 24,9 & 46,4 & b \\
\hline 12 & 67,50 & 2,42 & 1,24 & 2,31 & 61429 & 7143 & b & 66484 & b & 22,7 & 23,8 & 50,3 & b \\
\hline 13 & 67,50 & 2,46 & 1,39 & 2,28 & 59286 & 4286 & $\mathrm{c}$ & 65245 & $\mathrm{~b}$ & 18,3 & 23,9 & 45,8 & b \\
\hline 14 & 68,50 & 2,54 & 1,40 & 2,23 & 61429 & 7857 & b & 52525 & $\mathrm{c}$ & 25,3 & 24,3 & 40,6 & b \\
\hline 15 & 67,50 & 2,49 & 1,32 & 2,35 & 61429 & 2857 & $\mathrm{c}$ & 76582 & $\mathrm{a}$ & 22,1 & 25,5 & 48,5 & b \\
\hline 16 & 69,00 & 2,07 & 1,08 & 1,86 & 53572 & 15000 & $\mathrm{a}$ & 30177 & $\mathrm{c}$ & 29,8 & 28,7 & 53,1 & b \\
\hline 17 & 68,00 & 2,31 & 1,25 & 1,91 & 60715 & 3572 & $\mathrm{c}$ & 57666 & $\mathrm{c}$ & 24,1 & 26,9 & 51,1 & b \\
\hline 18 & 67,00 & 2,47 & 1,37 & 2,03 & 56429 & 7143 & b & 56377 & $\mathrm{c}$ & 24,1 & 20,9 & 51,7 & b \\
\hline 19 & 68,00 & 2,32 & 1,34 & 2,07 & 50714 & 5714 & $\mathrm{c}$ & 56052 & $\mathrm{c}$ & 23,5 & 23,4 & 46,6 & b \\
\hline 20 & 68,50 & 2,44 & 1,36 & 2,29 & 53572 & 6429 & b & 57643 & $\mathrm{c}$ & 24,2 & 22,5 & 48,8 & b \\
\hline 21 & 67,50 & 2,33 & 1,20 & 2,11 & 58572 & 2143 & $\mathrm{c}$ & 55939 & $\mathrm{c}$ & 24,0 & 23,7 & 44,9 & b \\
\hline 22 & 67,50 & 2,51 & 1,36 & 2,26 & 67143 & 7143 & b & 78481 & $\mathrm{a}$ & 23,6 & 23,9 & 47,5 & b \\
\hline 23 & 67,50 & 2,37 & 1,20 & 2,29 & 53572 & 10000 & b & 50470 & $\mathrm{c}$ & 24,5 & 29,0 & 49,4 & b \\
\hline 24 & 67,50 & 2,35 & 1,26 & 2,14 & 58572 & 7857 & b & 70295 & $\mathrm{a}$ & 22,2 & 25,4 & 53,6 & b \\
\hline 25 & 67,50 & 2,41 & 1,30 & 2,25 & 48572 & 12143 & $\mathrm{a}$ & 50652 & $\mathrm{c}$ & 23,6 & 27,5 & 70,7 & $\mathrm{a}$ \\
\hline 26 & 68,00 & 2,11 & 1,19 & 2,11 & 59286 & 3572 & $\mathrm{c}$ & 57326 & $\mathrm{c}$ & 20,0 & 22,5 & 47,0 & b \\
\hline 27 & 67,50 & 2,23 & 1,13 & 2,36 & 57857 & 2857 & $\mathrm{c}$ & 46575 & $\mathrm{c}$ & 18,8 & 23,4 & 48,2 & b \\
\hline 28 & 67,00 & 2,34 & 1,28 & 2,56 & 65000 & 5714 & $\mathrm{c}$ & 62564 & b & 20,7 & 26,5 & 46,9 & b \\
\hline 29 & 68,50 & 2,30 & 1,17 & 2,10 & 58572 & 1429 & $\mathrm{c}$ & 53822 & $\mathrm{c}$ & 18,2 & 22,8 & 48,1 & b \\
\hline 30 & 68,50 & 2,36 & 1,23 & 1,17 & 62143 & 14286 & $\mathrm{a}$ & 46941 & $\mathrm{c}$ & 27,5 & 24,5 & 52,8 & b \\
\hline 31 & 66,50 & 2,42 & 1,24 & 2,39 & 60000 & 1429 & $\mathrm{c}$ & 53386 & $\mathrm{c}$ & 21,2 & 26,8 & 54,3 & b \\
\hline 32 & 67,50 & 2,32 & 1,33 & 2,41 & 61429 & 2858 & $\mathrm{c}$ & 76940 & $\mathrm{a}$ & 23,3 & 23,7 & 49,8 & $\mathrm{~b}$ \\
\hline Média & 67,66 & 2,38 & 1,28 & 2,17 & 59308 & 4933 & & 60590 & & 23,5 & 24,6 & 49,5 & \\
\hline $\mathrm{CV}$ & 1,37 & 4,11 & 7,85 & 7,64 & 7,63 & 61,68 & & 11,22 & & 13,45 & 12,84 & 6,39 & \\
\hline
\end{tabular}

* Médias não seguidas pela mesma letra diferem de Scott-Knott $(\mathrm{P}<0,05)$.

$\mathrm{DF}=$ dias para o florescimento; $\mathrm{EP}=$ estatura de planta $(\mathrm{m}) ; \mathrm{EE}=$ estatura de espiga $(\mathrm{m}) ; \mathrm{DC}=$ diâmetro de colmo $(\mathrm{cm}) ; \mathrm{NP}=$ número de plantas por hectare; $\mathrm{NPQA}=$ número de plantas quebradas mais acamadas; $\mathrm{MV}=$ matéria verde $(\mathrm{kg} / \mathrm{ha}) ; \mathrm{MSCOL}=$ matéria seca do colmo (\%); MSFV = matéria seca de folha verde (\%); MSESP = matéria seca de espiga (\%); CV = coeficiente de variação $(\%)$.

Avaliando 30 genótipos de milho para a produção de silagem, em sete locais diferentes, Mittelmann et al. (2005) concluíram que existe variabilidade genotípica e que o desempenho individual é influenciado pela interação genótipo $x$ ambiente, indicando a necessidade de uma regionalização da recomendação para o cultivo.

A escolha de um determinado genótipo para a produção de silagem depende de objetivos específicos no que tange ao ajuste da dieta a ser fornecida. Como nenhum dos caracteres bromatológicos apresentou diferença significativa, ao utilizar-se a média dos genótipos, verifica-se que os eles estão dentro dos parâmetros descritos por Ball et al. (2007), os quais informam que uma silagem rica em grãos de boa qualidade energética possui de 60 a $70 \%$ de NDT, e o presente estudo apresenta $69,1 \%$. 
Vieira et al.

Tabela 5. Média dos caracteres avaliados dos genótipos do Ensaio Centro Superprecoce

\begin{tabular}{|c|c|c|c|c|c|c|c|c|c|c|c|c|c|c|}
\hline Gen & MSST & MSSENS & $\mathrm{EF}$ & \multicolumn{2}{|c|}{ MSPL } & MSH & & UM & MSO & PB & FDA & FDN & NDT & ELL \\
\hline 1 & 28,8 & 25,0 & 633,5 & 29,6 & $b^{*}$ & 23,1 & $\mathrm{a}$ & 73,5 & 26,6 & 6,85 & 29,5 & 49,5 & 67,4 & 1,5 \\
\hline 2 & 30,8 & & 594,0 & 33,5 & $\mathrm{a}$ & 20,7 & $\mathrm{a}$ & 67,4 & 32,6 & 8,00 & & 41,7 & & 1,7 \\
\hline 3 & 27,4 & 29,0 & 507,5 & 29,5 & b & 16,5 & b & 70,5 & 29,5 & 6,62 & 25,1 & 46,8 & 70,3 & 1,6 \\
\hline 4 & 30,3 & 28,0 & 535,5 & 30,9 & b & 23,2 & $\mathrm{a}$ & 68,6 & 31,4 & 8,18 & 21,2 & 42,9 & 72,9 & 1,7 \\
\hline 5 & 30,8 & 6,0 & 426,5 & 33,5 & $\mathrm{a}$ & 21,4 & $\mathrm{a}$ & 71,3 & 28,7 & 7,61 & 25,0 & 47,5 & 70,4 & 1,6 \\
\hline 6 & & & 397,0 & & b & 22,3 & $\mathrm{a}$ & 68,9 & 31,1 & 7,40 & 23,5 & 43,8 & 71,4 & 1,7 \\
\hline 7 & 30,8 & 29,0 & 497,5 & 35,3 & $\mathrm{a}$ & 21,9 & $\mathrm{a}$ & 67,9 & 32,1 & 7,81 & 28,3 & 51,9 & 68,2 & 1,5 \\
\hline 8 & 1,3 & & 5 & 34,0 & $\mathrm{a}$ & 23,2 & $\mathrm{a}$ & 67,2 & 32,8 & 7,06 & 24,2 & 46,3 & 71,0 & 1,6 \\
\hline 9 & 8,6 & & 439,5 & 33,8 & $\mathrm{a}$ & 21,2 & $\mathrm{a}$ & 66,9 & 33,2 & 8,17 & 19,7 & 40,2 & 73,9 & 1,8 \\
\hline 10 & & & & +2 & $\mathrm{a}$ & 8,0 & b & 72,3 & 27,7 & 7,87 & 24,5 & 46,6 & 70,7 & 1,6 \\
\hline 11 & & & & ,0 & b & 20,5 & $\mathrm{a}$ & 77,2 & 22,8 & 7,38 & 26,0 & 48,3 & 69,8 & 1,6 \\
\hline 12 & & & & & b & 20,1 & $\mathrm{a}$ & 70,3 & 29,8 & 7,30 & 27,0 & 49,6 & 69,1 & 1,6 \\
\hline 13 & 27,0 & 3,0 & 503,5 & 26,8 & b & 17,4 & b & 74,5 & 25,6 & 6,48 & 36,2 & 61,0 & 62,9 & 1,3 \\
\hline 14 & & & 494,0 & 28,4 & b & 14,9 & b & 70,1 & 29,9 & 8,34 & 26,0 & 48,7 & 69,7 & 1,6 \\
\hline 15 & & & 460,0 & 30,8 & b & 3,7 & $\mathrm{a}$ & 70,4 & 29,6 & 7,5 & 26,8 & 49,5 & 69,2 & 1,6 \\
\hline 16 & & & & & $\mathrm{a}$ & & b & 69,2 & 30,8 & 7,96 & 6 & 48,7 & & 1,6 \\
\hline 17 & & & 02,5 & 32,9 & $\mathrm{a}$ & 9,0 & b & 72,5 & 27,5 & 7,27 & 27,6 & 50,7 & 68 & 1,6 \\
\hline 18 & 6 & & 6,5 & 1,0 & b & 17,4 & b & 72,2 & 27,8 & 6,24 & 36,1 & 60,2 & 63,0 & 1,3 \\
\hline 19 & $t, 0$ & & 542,5 & 30,9 & b & 17,3 & b & 72,9 & 27,2 & 6,76 & 27,8 & 50,6 & 68,6 & 1,5 \\
\hline 20 & & & & & b & & b & 74,2 & 25,8 & 7,34 & 29,5 & 54,3 & & 1,5 \\
\hline 21 & & & & 30,1 & b & 16,8 & b & 74,4 & 25,6 & 6,73 & 27,1 & 51,2 & & 1,6 \\
\hline 22 & 6,2 & 22,0 & 491,0 & 30,1 & b & 23,6 & $\mathrm{a}$ & 73,9 & 26,1 & 7,02 & 32,0 & 55,0 & 65,8 & 1,4 \\
\hline 23 & 30,6 & 26,0 & 430,5 & 34,3 & $\mathrm{a}$ & 17,3 & b & 71,5 & 28,5 & 7,58 & 25,1 & 47,8 & 70,4 & 1,6 \\
\hline 24 & & & & & b &, 3 & $\mathrm{a}$ & 70,4 & 29,7 & 7,29 & 27,7 & 51,1 & 68 & 1,6 \\
\hline 25 & & & & & $\mathrm{a}$ & & $\mathrm{a}$ & 71,2 & 28,8 & 6,97 & 29,6 & 52,8 & 67,4 & 1,5 \\
\hline 26 & & & 373,0 & 29,9 & b & 17,1 & b & 73,4 & 26,6 & 7,51 & 26,9 & 49,8 & 69,2 & 1,6 \\
\hline 27 & 27,0 & 27,0 & 484,5 & 29,2 & b & 13,6 & b & 72,3 & 27,7 & 6,27 & 29,3 & 51,6 & 67,5 & 1,5 \\
\hline 28 & & & & 30,3 & b & 18,9 & b & 67,7 & 32,3 & 7,77 & 22 & 43,4 & 72,3 & 1,7 \\
\hline 29 & & & & 29,2 & b & 15,7 & b & 75,1 & 25,0 & 6,31 & 29,8 & 52,9 & 67,3 & 1,5 \\
\hline 30 & & & & 36,1 & $\mathrm{a}$ & 17,0 & b & 68,1 & 31,9 & 7,89 & 23 & 45,8 & 71,7 & 1,7 \\
\hline 31 & 29,1 & 27,0 & 395,0 & 33,2 & $\mathrm{a}$ & 17,8 & b & 70,2 & 29,9 & 7,21 & 25,6 & 47,9 & 70,0 & 1,6 \\
\hline 32 & 29,1 & 26,0 & 496,0 & 31,1 & $\mathrm{~b}$ & 23,8 & $\mathrm{a}$ & 72,3 & 27,7 & 6,21 & 31,6 & 54,3 & 66,0 & 1,4 \\
\hline Média & 28,5 & 28,0 & 473,7 & 31,8 & & 19,2 & & 71,2 & 28,8 & 7,28 & 26,9 & 49,4 & 69,1 & 1,6 \\
\hline $\mathrm{CV}$ & 11,1 & 11,48 & 19,19 & 6,28 & & 13,9 & & 3,99 & 9,85 & 11,2 & 19,8 & 12,5 & 5,03 & 9,3 \\
\hline
\end{tabular}

* Médias não seguidas pela mesma letra diferem de Scott-Knott $(\mathrm{p}<0,05)$.

** MSST $(\%)=$ matéria seca das plantas trituradas para silagem; MSSENS $(\%)=$ matéria seca do material ensilado; EF $(\mathrm{g})=$ liberação de efluentes; MSPL $(\%)=$ matéria seca de planta total; $\mathrm{MSH}(\mathrm{t} / \mathrm{ha})=$ matéria seca por hectare, UM, $(\%)=$ umidade; MSO $(\%)$ = matéria seca original, PB $(\%)=$ proteína bruta, FDA $(\%)=$ fibra em detergente ácido, FDN $(\%)=$ fibra em detergente neutro; $\operatorname{NDT}(\%)=$ nutrientes digestíveis totais; ELL = energia líquida de lactação e coeficiente de variação $(\mathrm{CV})$.

Os teores de fibra bruta devem variar de, no mínimo, 65,3 e de, no máximo, 72,8\%. Além disso, devem possuir bons padrões de fermentação e apresentar elevado valor nutritivo destacando-se valores médios das características de PB (7-9\%), FDA (23-30\%), FDN (48-58\%), NDT $(66 \%-71 \%)$. Nesse sentido, a maioria dos genótipos avaliados possui valores médios semelhantes aos valores apresentados pela literatura, devendo-se utilizar o caractere produção de matéria seca para a indicação de cultivares de milho, em que se destacam os genótipos: AS 1555 YG, AS 1572 YG, 30A37, 30A77, 20A78, Dx 908, Dx 603, 2A550, 2B433, AL2007A, Embrapa 1F640, PRE 22T10, PREXT0109, PRE 22D11, DKB330 YG (Test), que possuíram as maiores produtividades diferentes estatisticamente dos demais. 


\section{CONCLUSÕES}

A escolha do genótipo para a produção de silagem não deve ser baseada no grupo genético ou nas características de dureza do grão, mas sim nas características individuais dos cultivares. A produção de matéria seca foi superior para os genótipos AS 1555 YG, AS 1572 YG, 30A37, 30A77, 20A78, Dx 908, Dx 603, 2A550, 2B433, AL2007A, Embrapa 1F640, PRE 22T10, PREXT0109, PRE 22D11, DKB330 YG (Test).

\section{AGRADECIMENTOS}

À Nutron Alimentos, pela realização das análises das amostras de silagem pelo método NIRS; à Embrapa Milho e Sorgo, pela disponibilização das sementes; ao CNPq, à Fundação Araucária e à UTFPR, pela concessão de bolsas de iniciação científica e produtividade.

\section{REFERÊNCIAS}

BALL, D.M.; HOVELAND, C.S.; LACEFIELD, G.D. Southern forages. 4.ed. Lawrenceville, Georgia: International Plant Nutrition Institute (IPNI), 2007. $322 \mathrm{p}$.

BAL, M.A.; SHAVER, R.D.; SHINNERS, K.J. et al. Stage of maturity, processing, and hybrid effects on ruminal in situ disappearance of whole - plant corn silage. An. Feed Sc. Techn., v.86, p.83-84, 2000.

BELEZE, J.R.F.; ZEOULA, L.M.; CECATO, U. et al. Avaliação de cinco híbridos de milho (Zea mays, L.) em diferentes estádios de maturação, produtividade, características morfológicas e correlações. Rev. Bras. Zootec., v.32, p.529-537, 2003.

BERZAGHI, P.; COZZI, G.; ANDRIGHETTO, I. The use of near infrared analysis for in situ studies. J. Dairy Sci., v.80, p.3263-3270, 1997.

BRUNO, O.A.; ROMERO, L.A.; GAGGIOTTI, M.C. et al. Cultivares de sorgos forrajeros para silaje. 1. Rendimento de matéria seca y valor nutritivo da la planta. Rev. Argentina Prod. Anim., v.12, p.157-162, 1989.

CRUZ, C.D. Programa Genes: Estatística experimental e matrizes. Viçosa: Editora UFV. 2006. 285p.

EMBRAPA - Empresa Brasileira de Pesquisa Agropecuária. Disponível em: <http://www.cnpms.embrapa.br/milho/cultivares/ index.php> Acessado em: 01/09/2010.

FLARESSO, J.A.; GROSS, C.D.; ALMEIDA, E.X. Cultivares de milho (Zea mays L.) e sorgo (Sorghum bicolor (L.) Moench.) para ensilagem no Alto Vale do Itajaí, Santa Catarina. Rev. Bras. Zootec., v.29, p.1608-1615, 2000.

FREITAS, F.C.L.; SANTOS, M.V.; MACHADO, A.F.L. et al. Comportamento de cultivares de milho no consórcio com Brachiária brizantha na presença e ausência de Foramsulfuron + Iodosulfuron-methyl para o manejo da forrageira. Plan. Dan., v.26, p.215-221, 2008.

INSTITUTO Paranaense de Desenvolvimento Econômico e Social-IPARDES. Disponível em: http:

<www.ipardes.gov.br/modules/conteudo/conteud o.php> Acessado em: 20/09/2009.

JAREMTCHUK, A.R.; JAREMTCHUK, C.C.; BAGLIOLLI, B. et al. Características agronômicas e bromatológicas de vinte genótipos de milho (Zea mays L.) para silagem na região leste paranaense. Acta Scient. Anim. Sciences., v.27, p.181-188, 2005.

MARTIN, T.N.; STORCK, L. Análise das pressuposições do modelo matemático em experimentos agrícolas no delineamento blocos ao acaso. In: MARTIN, T.N.; ZIECH, M.F. (Org.). Sistemas de Produção Agropecuária. UTFPR, 2008, v.1, p.177-196.

MELLO, R.; NÖRNBERG, J.L.; ROCHA, M.G. Potencial produtivo e qualitativo de híbridos de milho, sorgo e girassol para ensilagem. Rev. Bras. Agroc., v.10, p.87-95, 2004.

MELLO, W.M.C.; VON PINHO, R.G.; CARVALHO, M.L.M. et al. Avaliação de cultivares de milho para produção de silagem na região de Lavras-MG. Cienc. Agrotec., v.23, p.31-39, 1999.

MITTELMANN, A.; SOUZA SOBRINHO, F.; SILVA E OLIVEIRA, J. et al. Avaliação de híbridos comerciais de milho para utilização como silagem na região sul do Brasil. Cien. Rural, v.35, p.684-690, 2005.

MORAES, G.J. COSTA, C. MEIRELLES, P.R.L.et al.) Produtividade e valor nutritivo das plantas de milho de textura dentada ou dura em três estádios de colheita para silagem. Bol. Ind. An., v.65, p.155-166, 2008. 
MÜLBACH， P.R.F. Silagem: produção com controle de perdas. In: LOBATO, J.F.P.; BARCELLOS, J.O.J.; KESSLER, A.M. et al. (Eds.) Produção de bovinos de corte. Porto Alegre: EDIPUCRS, 1999. p.97-120.

NUSSIO, L.G.; CAMPOS, F.P.; DIAS, F.N. Importância da qualidade da porção vegetativa no valor alimentício da silagem de milho. In: Simpósio sobre produção e utilização de forragens conservadas, 1., 2001, Maringá. Anais... Maringá, 2001, p.127-145.

ROSA, J.R.P.; SILVA, J.H.S.; RESTLE, J. et al. Avaliação do comportamento agronômico da planta e valor nutritivo da silagem de diferentes híbridos de milho (Zea mays, L.). Rev. Bras. Zootec., v.33, p.302-312, 2004.

ROSSI JÚNIOR, P.; FUGISAWA, A.C.; SCHOGOR, A.L.B. et al. Digestibilidade aparente de dois cultivares de milho, cortados em diferentes alturas, submetidos à ensilagem. Arch. Vet. Sc., v.11, p.58-61, 2006.
SANTOS, H.G.; BHERING, S.B.; BOGNOLA, I.A. et al. Distribuição e ocorrência dos solos no Estado do Paraná. In: BHERING, S.B.; SANTOS, H.G. (Ed.). Mapa de solos Estado do Paraná: legenda atualizada. Rio de Janeiro: Embrapa Solos., 2008. p.49-74.

SENGER, C.C.D.; MÜHLBACH, P.R.F.; BONNECARRERE SANCHEZ, L.M. et al. Composição química e digestibilidade 'in vitro' de silagens de milho com distintos teores de umidade e níveis de compactação. Cienc. Rural, v.35, p.1393-1399, 2005.

SOUZA, G.A.; FLEMMING, J.S.; FLEMMING, R. et al. Avaliação de cultivares de milho para produção de silagem de alta qualidade. Arch. Vet. Scie., v.5, p.107-110, 2000.

VAN SOEST, P.J. Nutritional ecology of the ruminant. 2nd ed. Ithaca New York: Cornell University Press, 1994. 476p. 